\title{
MODELLING OF STEEL-CONCRETE BRIDGES SUBJECTED TO A MOVING HIGH-SPEED TRAIN
}

\author{
Szurgott, P., ,\# \& Bernacki, P.** \\ *Faculty of Mechanical Engineering, Military University of Technology, Warsaw, Poland \\ *** Tomplan Group Sp. z o.o. sp. k., Lubochnia, Poland \\ E-Mail: piotr.szurgott@wat.edu.pl, bernacki.pawel@gmail.com (" Corresponding author)
}

\begin{abstract}
In the present study, a method for modelling and simulating the transient vibrations of a system comprising a steel-concrete bridge, ballasted track and moving high-speed train is proposed. The proposed approach uses advanced LS-DYNA simulation software based on finite element (FE) analysis and is applied to a series of single-span simply supported steel-concrete bridges. The theoretical span lengths of the bridges are 15, 18, 21, 24 and 27 metres. The bridge-track-train system is assumed to be fully symmetric. The reinforced concrete platform is homogenized based on the quasi-uniform distribution of the rebars in the specified sections. The bridge FE model does not include transverse bracing between the steel main beams, and the track rail-line axes are rectilinear. The ICE-3 highspeed multiple-unit train is considered at service velocities ranging between 200 and $300 \mathrm{~km} / \mathrm{h}$. FE analysis reveals deflection of the bridge at mid span. The results are plotted as a function of train velocity, thus permitting an assessment of the dynamic response of the bridge for each span length. (Received in August 2019, accepted in December 2019. This paper was with the authors 2 weeks for 1 revision.)
\end{abstract}

Key Words: Railway Vehicle, Vehicle Track Interaction, Railway Track, Train Passing, Simulation

\section{INTRODUCTION}

Modelling bridge-track-train (BTT) bridge systems is challenging due to the large number of parameters describing each component of the system. Many of these parameters are difficult to identify or are not widely disseminated by manufacturers or research institutions. This complexity hinders realistic predictions of the dynamic response of a bridge to the movement of a high-speed train [1].

A variety of methods and approaches for analysing the dynamics of railway bridges were developed in the latter half of the $20^{\text {th }}$ century $[2,3]$. These efforts primarily modelled quasi steady-state and transient vibrations of BTT systems and frequently adopted simple problemoriented computer tools for simulations. Since the beginning of the $21^{\text {st }}$ century, scientists have increasingly used commercial CAE systems to solve these problems. For example, Cheng et al. [4] developed a 2D linear model of a BTT system including coupled oscillators and an Euler beam. For a cable-stayed railway bridge, Au et al. [5] applied a six-degree-offreedom (6-DOF) Matsuura model for rail-vehicle modelling. Zhang et al. [6] proposed a BTT system simulation method in which a beam finite element (FE) model was applied for the bridge superstructure and a 3D multi-body rail-vehicle model with vertical and horizontal suspension systems was considered. For the TGV train, Song and Choi developed a modelling and simulation method that discretized continuous-beam bridges using beam FEs with 6 DOFs [7]. In a subsequent study, Song et al. [8] proposed a model for 3D FE analysis of the interactions between a high-speed train and bridge. The proposed model incorporated improved FEs describing the structural components of the bridge. Xia et al. [9] evaluated a dynamic interaction model of a system comprising a bridge and an articulated high-speed train. The model was verified by comparing the dynamic responses of the bridge and vehicles calculated according to the model with the values measured for a Thalys train crossing the Antoing Bridge in Belgium. In another application of FE analysis to a BTT system, Lee et al. 
[10] compared the dynamic responses of a railway bridge between a track model with 3D discrete support and one without. Rigueiro et al. [11] developed a model of a ballast-rail track system to investigate the effects of the interaction between a railway vehicle and bridge for a medium-span viaduct with simple supports. The ballasted rail track system was modelled by considering the horizontal and vertical rail stiffness, while the ballast, rail pad, sleepers, and ballast were modelled as linear springs, dampers or masses. By considering both a moving load model and dynamic analyses of the interaction between a bridge and vehicle models varying in sophistication, Liu et al. [12] identified several parameters influencing the response of the bridge to the dynamic train-bridge interaction. Mikheev et al. [13] adopted CAE to analyse the dynamics of a coupled railway bridge-train model in which the bridge was considered a flexible multibody system based on FE analysis. To support systematic analyses of the safety and comfort of high-speed BTT systems, Zhai et al. [14] developed a framework comprising a model of BTT dynamic interactions and computer simulation software for predicting vertical and lateral dynamic responses. Podworna and Klasztorny developed a vibration theory and presented a random dynamic analysis of a series of different types of composite railway bridges under loading by a high-speed train; their theory encompassed the viscoelastic suspensions of the railway vehicles, the non-linear Hertz contact stiffness and one-sided contact between the wheelsets and rails, the viscoelastic and inertia features of the bridge, and the viscoelastic track structure [15, 16]. Salcher and Adam incorporated the influence of rail irregularities on BTT dynamic interactions by using ABAQUS to build a full $3 \mathrm{D}$ model of the bridge and MATLAB to model the vehicle subsystem and substructure coupling and solve the coupled system equations [17]. Cantero et al. [18] also used MATLAB to implement a model for calculating the coupled dynamic response of BTT systems. The model was validated by comparison with a commercial FE package and applied in numerical studies to illustrate its utility in examining the dynamic responses of a train and bridge.

These studies have revealed that the vibrations of BTT systems are transient, spatial and nonlinear. Currently, the design of railway bridges adopts separate spans for each track, with quasi-symmetrical cross-sections. Lateral vibrations of the vehicles are negligible due to the assumed rectilinear tracks. Consequently, it can be assumed although the BTT system is three-dimensional, its vibrations are symmetrical with respect to the vertical longitudinal plane. Moreover, computer-aided dynamic calculations should be applied to realistically predict the dynamic behaviour of BTT systems.

The present article presents a method for modelling and simulating the transient vibrations of a BTT system using advanced CAE systems. The proposed method was successfully used to model dynamic BTT system interactions considering different vehicle models [1, 19-23]. Moreover, the presented methodology has been positively validated experimentally on the real bridge structure - Polish viaduct KNI 140070 - subjected to the EuroCity EC114 train [22]. The simulated time-histories of displacements and accelerations have been compared to respective experimental waveforms. The positive experience prompted the authors to apply this method for other bridges and trains. The main purpose of the analyses presented in this paper was to apply the methodology to a series of single-span simply supported steel-concrete bridges with different span lengths subjected to a high-speed train. Simulations conducted, using proposed methodology, allow not only to determine the maximum deflection of the bridge, but also to estimate resonant velocities. Taking into consideration a sufficiently large number of different bridges and trains would allow determining the factors affecting the value of resonant velocities or, in general, the behaviour of the bridge. The results demonstrate that complete 3D FE modelling of bridges allows their behaviour to be observed more quickly and effectively compared with mathematical modelling alone. 


\section{RESEARCH OBJECTS}

The present study adopts the series of steel-concrete bridge types designed by Klasztorny [3] in accordance with PN-85/S-10030 and PN-82/S-10052 standards. Fig. 1 depicts representative bridges taken into consideration, with 15- (code: CB15), 18- (CB18), 21- (CB21), 24(CB24), and 27-metre (CB27) spans. All bridges in the series have identical cross-sections of the reinforced concrete platform but differ in the steel main beams. The width of the bottom flanges and the height of the web differ for each span length. The bottom flanges are enforced with two additional cover plates, and vertical ribs are welded to the web on both sides at 1.5 metre intervals. Full symmetry of the bridge was assumed in modelling; hence transverse bracing was omitted, and the bearings were unmovable in the lateral direction.
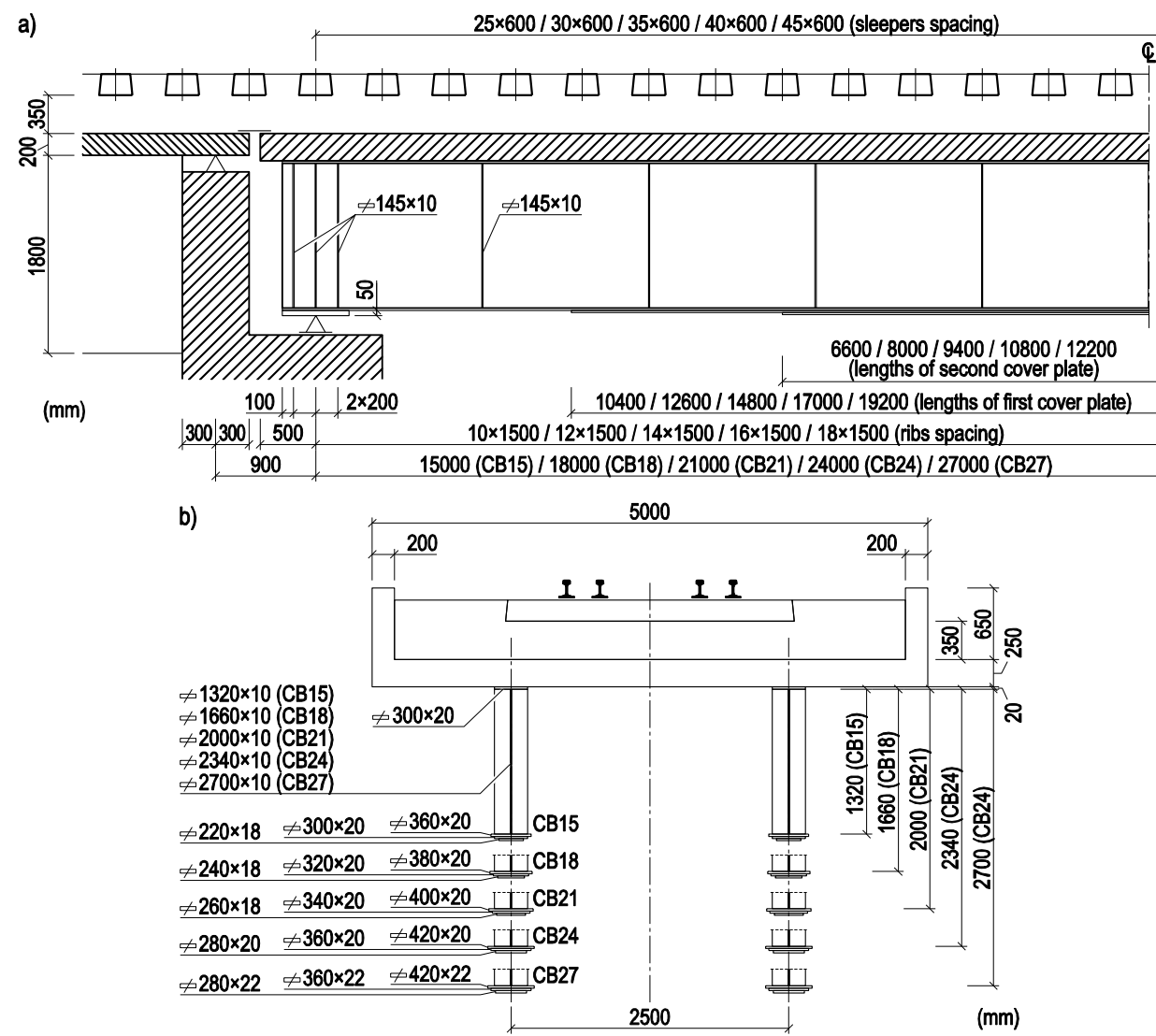

Figure 1: Schemes of the bridges under consideration: a) longitudinal section, b) cross-section.

Dimensions of the steel main beams are shown for all five variants.

The reinforced concrete platform is made of C35 (slab) and C30 (side-walls) concrete. The reinforcement with 18G2-b steel rebars is based on a real object, the KNI 140700 viaduct, which has been discussed in full by Szurgott et al. [22]. The platform is divided into zones as depicted in Fig. 2. Zones A, B, C and D have identical systems of rebar in the cross-section, but zones B1-B3 also include a system of rebar proportional to the span length. All zones feature a quasi-uniform distribution of reinforcement.

The ballasted track includes UIC 60 main rails fastened to B320 sleepers using a Vossloh 300-1 fastening system. In addition, 60E1 side rails fixed with SB3 fasteners are applied in the approach zones. The lengths of the side rails coincide with the lengths of the approach slabs before and after the bridge. Each approach slab is supported on the abutment wall on elastomeric bearings. The first-class ballast under the sleepers is 0.35 metres thick. In the approach zones of the embankment, a cement-stabilized subsoil is applied, a sand-gravel mix layer with a thickness of 0.2 metre is used outside the approach zones. 


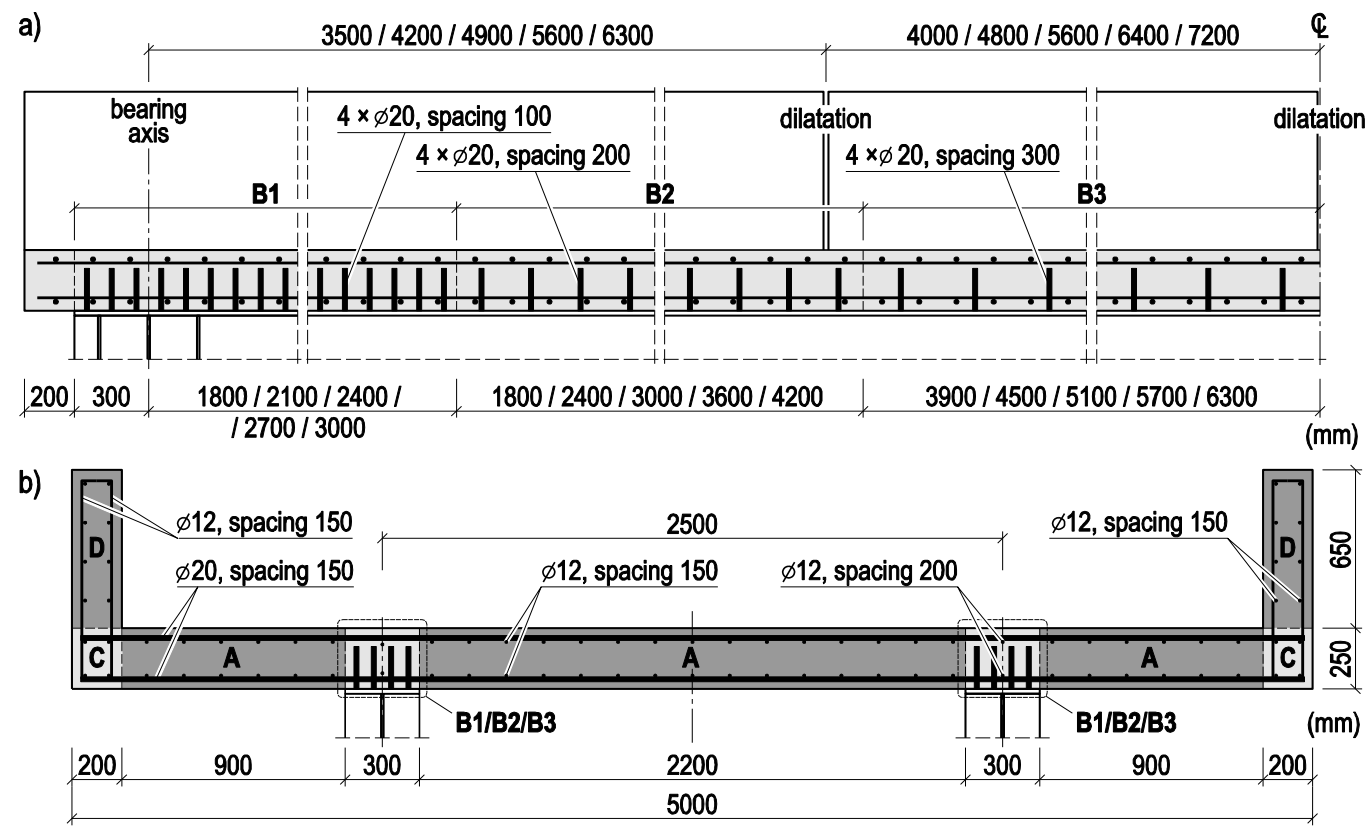

Figure 2: Structural reinforcement of the reinforced concrete platform: a) in the cross-section, b) in the longitudinal section.

The ICE-3 high-speed train manufactured by Siemens is selected as a representative. Instead of the end power heads found in previous generations, this train has motor bogies located on every second car. Therefore, the total weight is evenly distributed over each train unit, result in an axle load of approximately $160 \mathrm{kN}$. The maximum service velocity of the ICE-3 train is equal to $300 \mathrm{~km} / \mathrm{h}$ [24]. The trainset under consideration contains 8 carriages in the following configuration: power cars \#1 and \#8, transformer cars \#2 and \#7, converter cars \#3 and \#6, and intermediate cars \#4 and \#5.

Each power car and converter car are equipped with two motor bogie, while the transformer car and intermediate car have two trailer bogies. For both types of bogies, the structures of the primary and secondary suspension systems are the same. The primary suspension is equipped with two coil springs and two vertical dampers per axle (one per axle box), and the secondary system is equipped with two air springs and two vertical dampers per bogie.

\section{MODELLING OF THE BRIDGE-TRACK-TRAIN SYSTEM}

The methodology for physical modelling of the bridge was as follows. The reinforcement of the bridge platform was distributed quasi-uniformly in the respective zones as described above. Therefore, the slab and the side-walls of the platform were homogenized and simulated by orthotropic elastic materials [25]. The materials were specified independently for zones A, B1, B2, B3, C and D, and the following nine material constants were determined for each zone: Young's moduli $\left(E_{x}, E_{y}, E_{z}\right)$, Poisson's ratios $\left(v_{y x}, v_{z x}, v_{z y}\right)$ and shear moduli $\left(G_{x y}, G_{y z}, G_{z x}\right)$.

The mixture rule for orthotropic materials was applied in the homogenization process. The orthotropy directions coincided with the $x, y, z$ directions defined as follows: $x$ - longitudinal, $y$ - transverse, $z$-vertical. The fibre volume fraction $f_{i}$ of a given quasi-uniform zone was defined by the following formula:

$$
f_{i}=A_{z} / A
$$

where $A_{z}$ is the rebar cross-section area, $A$ is the area of a given zone (Fig. 2), and $i$ is the homogenization direction $(i=x, y, z)$.

The effective elastic constants of an orthotropic material can be calculated from the following formulae [25]: 


$$
\begin{gathered}
E_{x}=E_{s} f_{x}+E_{c}\left(1-f_{x}\right) \\
E_{y}=E_{s} f_{y}+E_{c}\left(1-f_{y}\right) \\
E_{z}=E_{s} f_{z}+E_{c}\left(1-f_{z}\right) \\
v_{y x}=\left[v_{s} f_{x}+v_{c}\left(1-f_{x}\right)\right] \cdot\left(E_{y} / E_{x}\right) \\
v_{z x}=\left[v_{s} f_{x}+v_{c}\left(1-f_{x}\right)\right] \cdot\left(E_{z} / E_{x}\right) \\
v_{z y}=\left[v_{s} f_{y}+v_{c}\left(1-f_{y}\right)\right] \cdot\left(E_{z} / E_{y}\right) \\
G_{x y}^{-1}=0.5 \cdot\left[\left(f_{x} / G_{s}\right)+\left(\left(1-f_{x}\right) / G_{c}\right)\right]+0.5 \cdot\left[\left(f_{y} / G_{s}\right)+\left(\left(1-f_{y}\right) / G_{c}\right)\right] \\
G_{y z}^{-1}=0.5 \cdot\left[\left(f_{y} / G_{s}\right)+\left(\left(1-f_{y}\right) / G_{c}\right)\right]+0.5 \cdot\left[\left(f_{z} / G_{s}\right)+\left(\left(1-f_{z}\right) / G_{c}\right)\right] \\
G_{z x}^{-1}=0.5 \cdot\left[\left(f_{z} / G_{s}\right)+\left(\left(1-f_{z}\right) / G_{c}\right)\right]+0.5 \cdot\left[\left(f_{x} / G_{s}\right)+\left(\left(1-f_{x}\right) / G_{c}\right)\right]
\end{gathered}
$$

where $E_{s}, E_{c}$ and $v_{s}, v_{c}$ are the Young's moduli and Poisson's ratios for steel and concrete, respectively.

The material constants for concrete and steel used in the FE model of the bridge are summarized in Table I. The values of the effective constants in the various zones of the RC platform are provided in Table II. The homogenized density was calculated based on percentage share of the rebar and the concrete in respective zones.

Table I: Material constants of concrete and steel used in the bridge structure [26].

\begin{tabular}{|c|c|c|c|c|}
\hline Material & $\begin{array}{c}\text { Young's modulus } \\
E(\mathrm{MPa})\end{array}$ & $\begin{array}{c}\text { Poisson's ratio } \\
v(-)\end{array}$ & $\begin{array}{c}\text { Shear modulus } \\
G(\mathrm{MPa})\end{array}$ & $\begin{array}{c}\text { Density } \\
\rho\left(\mathrm{kg} / \mathrm{m}^{3}\right)\end{array}$ \\
\hline B35 concrete & 34,600 & 0.167 & 14,800 & 2,500 \\
\hline B30 concrete & 32,600 & 0.167 & 14,000 & 2,500 \\
\hline 18G2-b steel & 200,000 & 0.300 & 77,000 & 7,850 \\
\hline St3S steel & 206,000 & 0.300 & 79,000 & 7,850 \\
\hline
\end{tabular}

Table II: Effective constants in the various zones of the reinforced concrete platform.

\begin{tabular}{|c|c|c|c|c|c|c|c|c|c|c|}
\hline \multirow{2}{*}{ Zone } & \multicolumn{2}{|c|}{ Young's modulus (MPa) } & \multicolumn{3}{|c|}{ Poisson's ratio $(-)$} & \multicolumn{2}{c|}{ Shear modulus $(\mathrm{MPa})$} & Density $\left(\mathrm{kg} / \mathrm{m}^{3}\right)$ \\
\cline { 2 - 12 } & $E_{x}$ & $E_{v}$ & $E_{z}$ & $v_{v x}$ & $v_{z x}$ & $v_{z y}$ & $G_{x y}$ & $G_{v z}$ & $G_{z x}$ & $\rho$ \\
\hline A & 35,597 & 37,370 & 35,177 & 0.176 & 0.166 & 0.159 & 14,937 & 14,922 & 14,857 & 2,623 \\
\hline B1 & 35,348 & 37,370 & 41,525 & 0.177 & 0.197 & 0.188 & 14,928 & 15,159 & 15,083 & 2,815 \\
\hline B2 & 35,348 & 37,370 & 38,062 & 0.177 & 0.180 & 0.172 & 14,928 & 15,029 & 14,954 & 2,718 \\
\hline B3 & 35,348 & 37,370 & 36,908 & 0.177 & 0.175 & 0.167 & 14,928 & 14,986 & 14,911 & 2,680 \\
\hline C & 36,095 & 37,370 & 35,846 & 0.174 & 0.167 & 0.162 & 14,956 & 14,947 & 14,900 & 2,679 \\
\hline D & 33,764 & 32,794 & 33,861 & 0.163 & 0.168 & 0.173 & 14,047 & 14,050 & 14,083 & 2,584 \\
\hline
\end{tabular}

Altair HyperMesh software was used to develop the bridge FE model. The steel main beams were meshed using four-node shell elements, and the platform was modelled using eight-node solid elements. Additional cover plates (see Fig. 1) of the beam bottom flanges were modelled as a duplicated layer of elements. Depending on the bridge length, the total number of elements ranged from 29384 (9400 - shell, 19984 - solid) for the shortest span to 62280 (27416 - shell, 34864 - solid) for the longest one. The roller and pivot bearings were modelled according to their respective constraints. Fig. 3 depicts the bridge model with the approach zone.

Physical modelling of the ballasted track was performed according to the following assumptions. The track axes were rectilinear in the unloading state, and irregularities of the rail surface were omitted. Beam elements that were deformable in flexure and shear were used for rail modelling. The fastening systems were simulated using massless one-dimensional vertically oriented springs and dampers. The springs were defined by a piecewise linear elastic relation between force and displacement whereas the dampers had a constant damping coefficient. The embankment was modelled using eight-node solid elements. The side and 
bottom boundary surfaces were unmovable. The sleepers were modelled as rigid beams with appropriate constraints to enable their vertical movement. The ballast layer was modelled as a vertical set of nonlinear springs and dampers (Fig. 3), with seven pairs of these elements under each sleeper. Finally, the ballast mass was distributed via mass elements into the nodes located in the bridge slab and the top subsoil layers. The geometric and mechanical parameters of the track were extracted from Klasztorny [2, 3], Niemierko et al. [27], and the Polish Standard [28] and are provided in Table III.

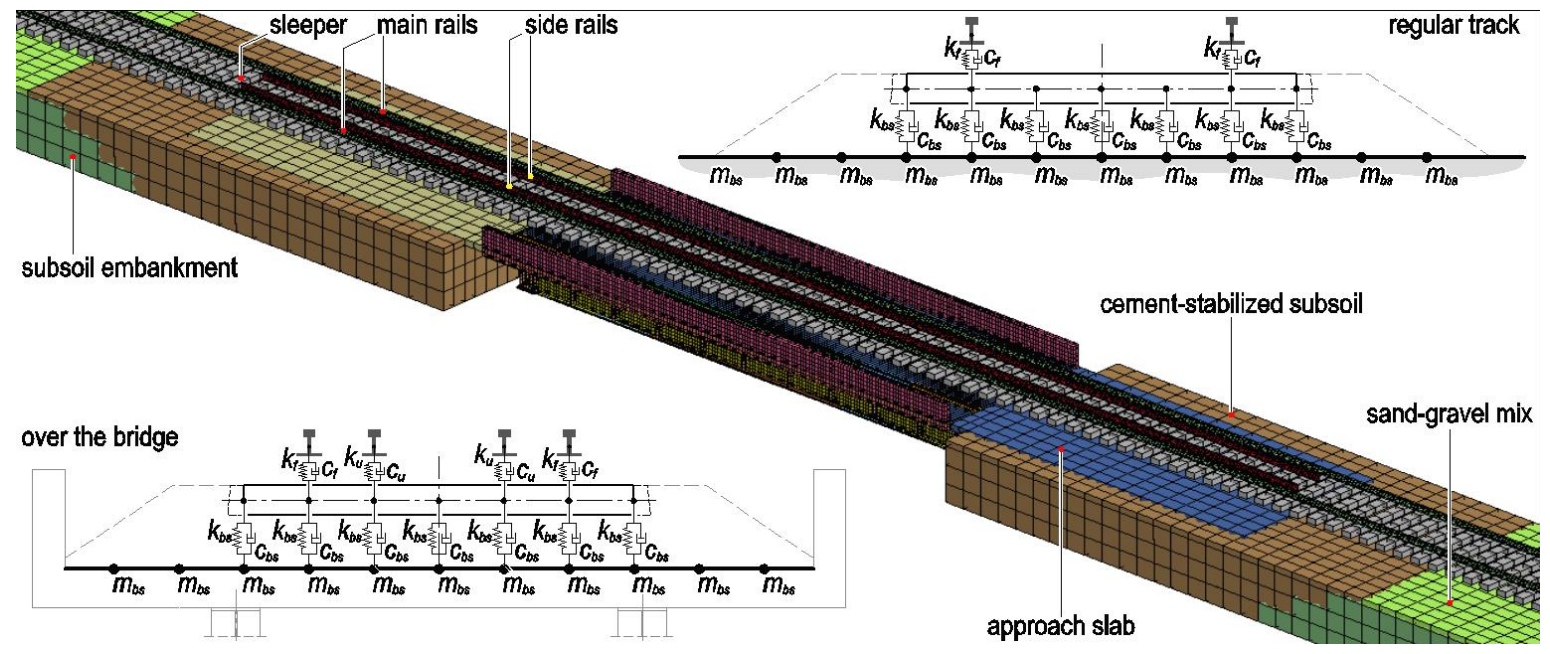

Figure 3: Finite element model of the bridge and approach zone and scheme of the track model.

Table III: Geometric and mechanical parameters of the track under consideration [2, 3, 27, 28]. Some designations correspond to the symbols in the physical model in Fig. 3.

The units correspond to those recommended in LS-DYNA software.

\begin{tabular}{|c|c|c|c|}
\hline Component & \multicolumn{2}{|c|}{ Parameter } & Value \\
\hline \multirow{5}{*}{ UIC60 rail } & \multicolumn{2}{|c|}{ principal moment of inertia, $I_{v}\left(\mathrm{~mm}^{4}\right)$} & $30.383 \times 10^{6}$ \\
\hline & \multicolumn{2}{|l|}{ cross-section area, $A\left(\mathrm{~mm}^{2}\right)$} & 7670 \\
\hline & \multicolumn{2}{|l|}{ mass density, $\rho\left(\mathrm{Mg} / \mathrm{mm}^{3}\right)$} & $7.85 \times 10^{-9}$ \\
\hline & \multicolumn{2}{|l|}{ Young's modulus, $E(\mathrm{MPa})$} & 210,000 \\
\hline & \multicolumn{2}{|l|}{ Poisson's ratio, $v(-)$} & 0.30 \\
\hline \multirow{4}{*}{ Vossloh 300-1 fastener } & \multirow{2}{*}{ static compression stiffness } & for load 0-18 kN, $k_{f 1}(\mathrm{~N} / \mathrm{mm})$ & 17,000 \\
\hline & & for load $18-53 \mathrm{kN}, k_{f 2}(\mathrm{~N} / \mathrm{mm})$ & 30,000 \\
\hline & \multicolumn{2}{|c|}{ static stretching stiffness, $k_{f 3}(\mathrm{~N} / \mathrm{mm})$} & 3,000 \\
\hline & \multicolumn{2}{|c|}{ equivalent viscous damping coefficient, $c_{f}(\mathrm{~N} \cdot \mathrm{s} / \mathrm{mm})$} & 2.5 \\
\hline \multirow{4}{*}{ SB3 fastener } & \multirow{2}{*}{ static compression stiffness } & for load $0-18 \mathrm{kN}, k_{u 1}(\mathrm{~N} / \mathrm{mm})$ & 50,000 \\
\hline & & for load $18-53 \mathrm{kN}, k_{u 2}(\mathrm{~N} / \mathrm{mm})$ & 100,000 \\
\hline & \multicolumn{2}{|c|}{ static stretching stiffness, $k_{u 3}(\mathrm{~N} / \mathrm{mm})$} & 3,000 \\
\hline & \multicolumn{2}{|c|}{ equivalent viscous damping coefficient, $c_{u}(\mathrm{~N} \cdot \mathrm{s} / \mathrm{mm})$} & 4.2 \\
\hline B320 sleeper & \multicolumn{2}{|l|}{ mass, $m_{s}(\mathrm{Mg})$} & 0.366 \\
\hline \multirow{4}{*}{ Ballast } & \multicolumn{2}{|l|}{ mass density, $\rho\left(\mathrm{Mg} / \mathrm{mm}^{3}\right)$} & $2.00 \times 10^{-9}$ \\
\hline & \multicolumn{2}{|c|}{ summer time static compression stiffness, $k_{b s}(\mathrm{~N} / \mathrm{mm})$} & 60000 \\
\hline & \multicolumn{2}{|c|}{ summer time static braking away stiffness, $k_{b s 0}(\mathrm{~N} / \mathrm{mm})$} & 0 \\
\hline & \multicolumn{2}{|c|}{ equivalent viscous damping coefficient, $c_{b s}(\mathrm{~N} \cdot \mathrm{s} / \mathrm{mm})$} & 14.0 \\
\hline \multirow{3}{*}{ Cement-stabilized subsoil } & \multicolumn{2}{|l|}{ mass density, $\rho\left(\mathrm{Mg} / \mathrm{mm}^{3}\right)$} & $2.265 \times 10^{-9}$ \\
\hline & \multicolumn{2}{|l|}{ Young's modulus, $E(\mathrm{MPa})$} & 325 \\
\hline & \multicolumn{2}{|l|}{ Poisson's ratio, $v(-)$} & 0.20 \\
\hline \multirow{3}{*}{ Sand-gravel mix layer } & \multicolumn{2}{|l|}{ mass density, $\rho\left(\mathrm{Mg} / \mathrm{mm}^{3}\right)$} & $1.90 \times 10^{-9}$ \\
\hline & \multicolumn{2}{|l|}{ Young's modulus, $E(\mathrm{MPa})$} & 150 \\
\hline & \multicolumn{2}{|l|}{ Poisson's ratio, $v(-)$} & 0.20 \\
\hline \multirow{3}{*}{ Subsoil embankment } & \multicolumn{2}{|l|}{ mass density, $\rho\left(\mathrm{Mg} / \mathrm{mm}^{3}\right)$} & $1.80 \times 10^{-9}$ \\
\hline & \multirow{2}{*}{\multicolumn{2}{|c|}{ Young's modulus, $E$ (MPa) }} & 82 \\
\hline & Poisson's ratio, $v(-)$ & & 0.20 \\
\hline
\end{tabular}


Altair HyperMesh and LS-PrePost pre-processors were used to develop the track FE model. The total length of 810 metres was determined based on the slowest passage of the train across the longest bridge. The following sections (Fig. 4) were extracted: the initial zone, in which the entire train was located at the beginning of analysis and the static wheel pressure was equal to zero; the loading zone (lasting $2 \mathrm{sec}$ ) in which the static wheel pressure increased from zero to its full value; the vibration stabilization zone (lasting $1 \mathrm{sec}$ ); the bridge zone, including the approach zones; the zone of free vibrations of the bridge (lasting $1 \mathrm{sec}$ ); and the end zone, corresponding to the final position of the train. 2 seconds time of the loading zone was assumed to obtain the smoothest impact of applying load on the model behaviour.

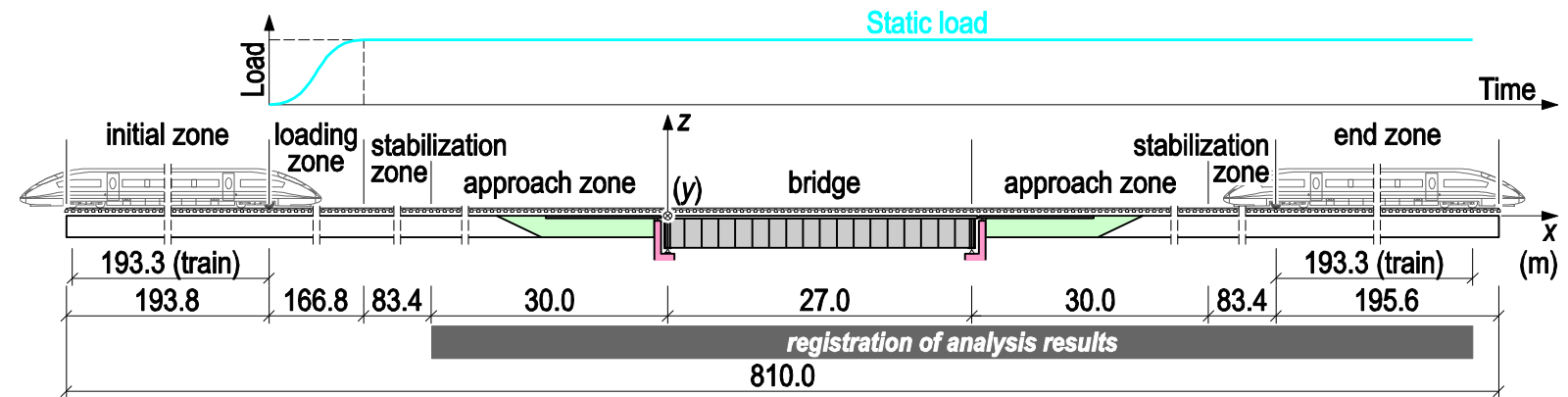

Figure 4: Specification of the track zones in the FE model.

The FE model of the trainset was developed using the LS-PrePost pre-processor. For each train unit, the model comprised the following: the carbody, bogie frames, wheelsets (considered as rigid bodies) and groups of massless discrete springs and dampers as the primary and secondary suspension systems. Appropriate translational and rotational joints were used to provide constraints and connections in the bogie components and between the bogie frame and the carbody. All mass components of the train unit were modelled using shell and beam elements. The wheelsets were modelled as vertical rigid beam elements. Fig. 5 depicts a side-view scheme of the FE model of the train unit. The values of the mechanical parameters of each train unit were obtained as described by Bachmann [29], Matsuura [30], Siemens [31], and Steimel [32] and are provided in Table IV. The FE model of the trainset contained 1568 finite elements and 80 lumped masses in total.

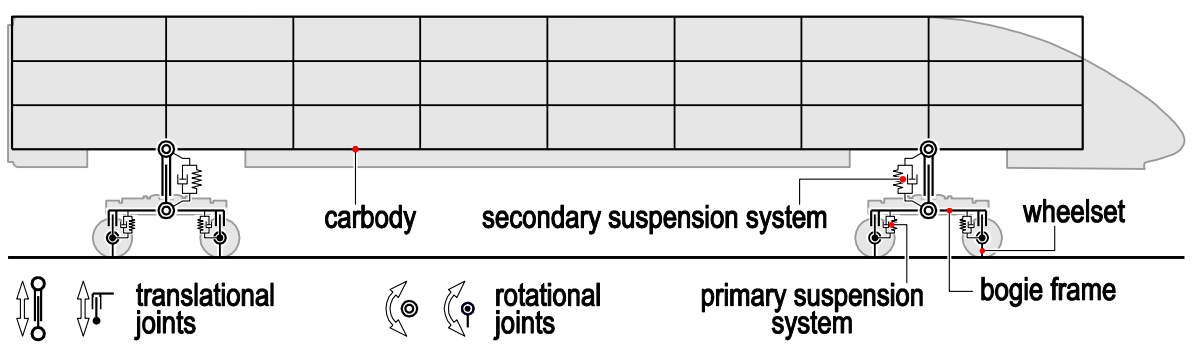

Figure 5: Scheme of the finite element model of the train unit.

The LS-DYNA modules RAIL_TRACK and RAIL_TRAIN [33], which allow approximate modelling of the track - train interaction without simulating wheel rotation, were applied. A set of vertical forces was imposed at the wheel - rail contact points, and each contact force $P(t)$ was increased from zero to the static load according to the following relation:

$$
P(t)=0.5 P_{0}\left[1-\cos \left(\pi t / t_{0}\right)\right] \text { for } t \in\langle 0,2 \mathrm{~s}\rangle
$$

where $P_{0}$ is the static load of a single wheel on the rail head and $t_{0}$ is the time required for the static load to increase to the full value. In the present study, $t_{0}=2 \mathrm{~s}$. 
Table IV: Mechanical parameters of the train units under consideration [29-32].

The units correspond to those recommended in LS-DYNA software.

\begin{tabular}{|c|c|c|}
\hline Parameter & $\begin{array}{c}\text { Carriage No. } \\
1,3,6,8 \\
\end{array}$ & $\begin{array}{c}\text { Carriage No. } \\
2,4,5,7\end{array}$ \\
\hline Carbody mass, $m_{b}(\mathrm{Mg})$ & 45.6 & 49.0 \\
\hline Bogie frame mass ${ }^{\mathrm{a})}, m_{f}(\mathrm{Mg})$ & 4.4 & 2.7 \\
\hline Wheelset mass ${ }^{\mathrm{b})}, m_{w}(\mathrm{Mg})$ & 2.4 & 2.4 \\
\hline Principal mass moment of inertia of the carbody, $I_{y b}\left(\mathrm{Mg} \cdot \mathrm{mm}^{2}\right)$ & $2.397 \times 10^{9}$ & $2.576 \times 10^{9}$ \\
\hline Principal mass moment of inertia of the bogie frame, $I_{y f}\left(\mathrm{Mg} \cdot \mathrm{mm}^{2}\right)$ & $5.420 \times 10^{6}$ & $3.330 \times 10^{6}$ \\
\hline Total equivalent vertical stiffness per axle, $k_{1}(\mathrm{~N} / \mathrm{mm})$ & 1,124 & 690 \\
\hline Total equivalent vertical damping per axle, $c_{1}(\mathrm{~N} \cdot \mathrm{s} / \mathrm{mm})$ & 8.8 & 5.4 \\
\hline Total equivalent vertical stiffness per bogie, $k_{2}(\mathrm{~N} / \mathrm{mm})$ & 561 & 603 \\
\hline Total equivalent vertical damping per bogie, $c_{2}(\mathrm{~N} \cdot \mathrm{s} / \mathrm{mm})$ & 27 & 29 \\
\hline
\end{tabular}

The service velocity of the train model was specified as a constant according to two options: INITIAL_VELOCITY at $t=0$ and PRESCRIBED_MOTION_RIGID at $t>0$. The FE models of the train unit components were developed with full conformity to the actual objects in terms of the masses and principal mass moments of inertia.

\section{SIMULATIONS OF TRANSIENT VIBRATIONS OF THE SYSTEM}

Simulations of the transient vibrations of the system under consideration were performed using advanced LS-DYNA simulation software. During the analyses, the nodal displacement at the mid span of the bridge was recorded [34]. The simulations were carried out for velocities between 200 and $300 \mathrm{~km} / \mathrm{h}$ in increments of $10 \mathrm{~km} / \mathrm{h}$. However, in some cases, an increment of $5 \mathrm{~km} / \mathrm{h}$ was required. Extreme values of the vertical deflections are depicted in Fig. 6.

The resonance velocity of the system varied depending on the bridge span length. This resonance was most evident for the shortest bridge. The waveforms for deflection (Fig. 7) were similar to those for the longitudinal normal stresses, which are not presented in this paper, due to the obvious interdependence of these parameters. Hence, it is sufficient to consider only deflection or stress to assess the behaviour of the bridge. Fig. 8 presents the contours of the resultant displacement for the bridge models at selected time points.

\section{SUMMARY AND CONCLUSIONS}

In this study, an FE model of a BTT system was developed and applied in simulations. The proposed methodology was previously successfully validated experimentally on the actual object by Szurgott et al. [22]. The methodology is based on the following assumptions:

- rectilinearity of the track rail-line axes and no track irregularities,

- full symmetry of the bridge superstructure,

- homogenization of the reinforced concrete platform of the bridge,

- application of vertically oriented massless one-dimensional nonlinear discrete elements for track substructure modelling,

- modelling of the train as a group of rigid bodies connected to each other with appropriate joints,

- application of LS-DYNA software modules that permit the track - train interaction to be modelled without simulation of the wheels' rotation. 

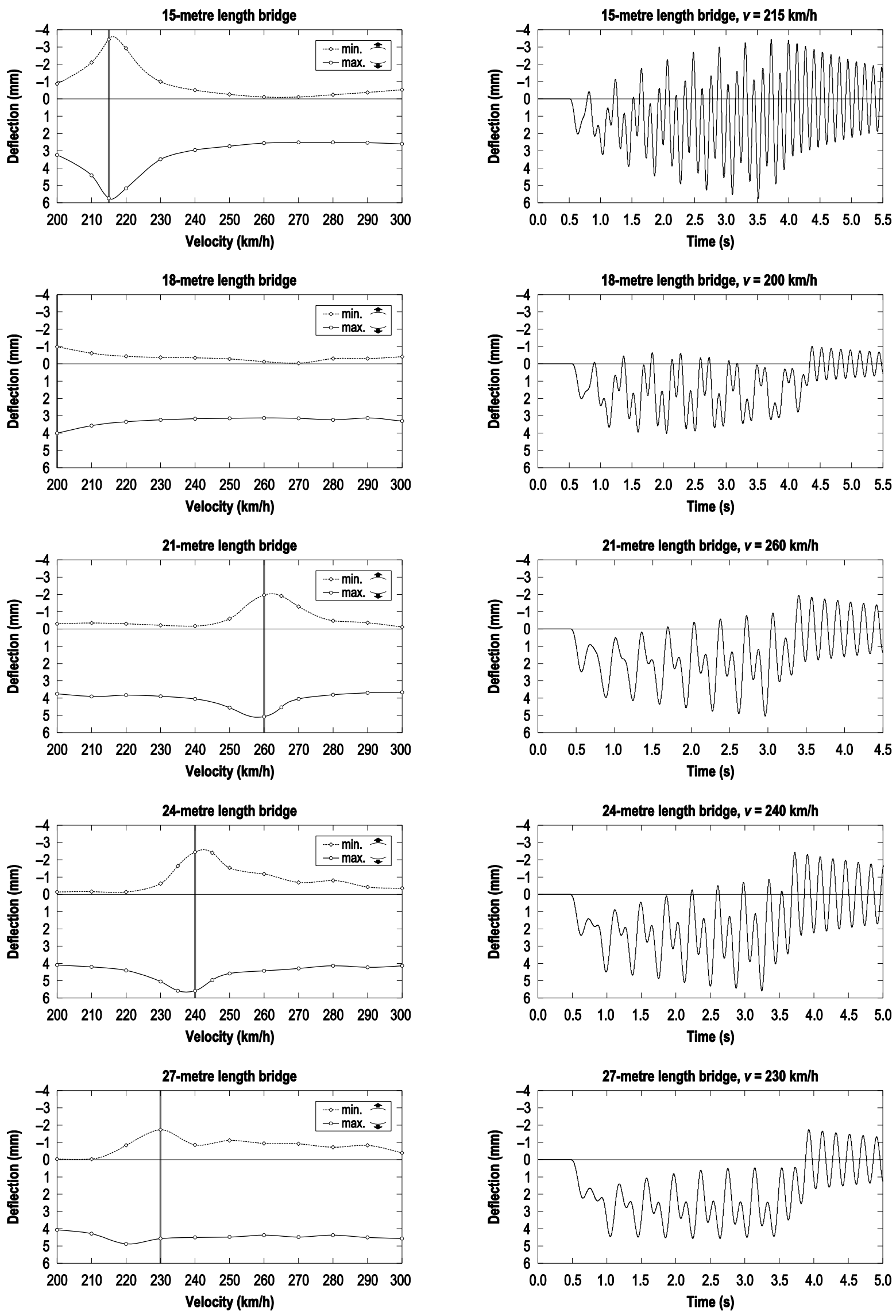

Figure 6: Extreme vertical deflections at mid span registered for service velocities of $200-300 \mathrm{~km} / \mathrm{h}$.

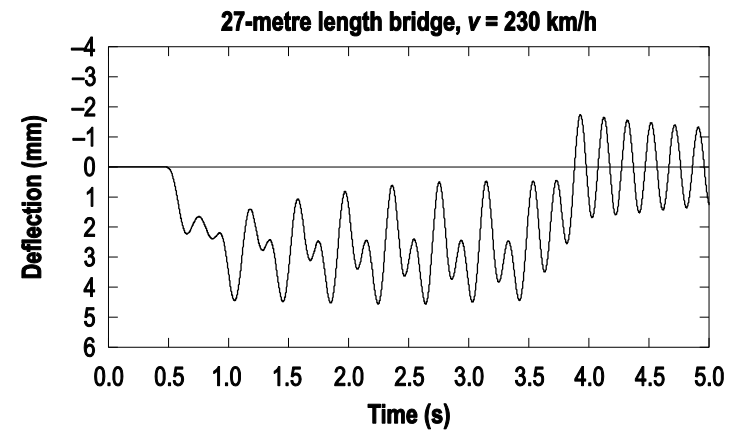

Figure 7: Time histories of vertical deflection at mid span for velocities causing max deflection. 


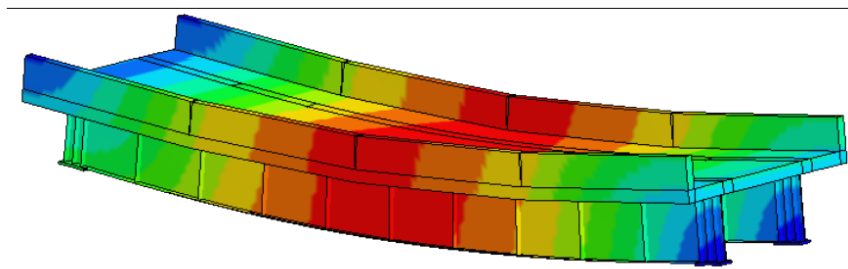

15-metre length bridge, $v=215 \mathrm{~km} / \mathrm{h}, t=3.10 \mathrm{~s}$ resultant displacement (mm)

0.58 0.00

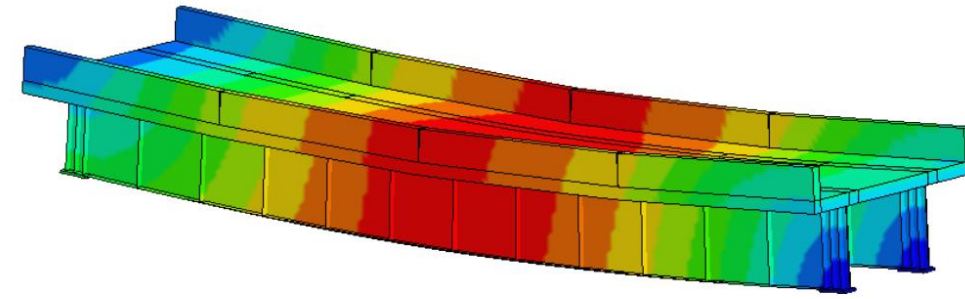

18-metre length bridge, $v=200 \mathrm{~km} / \mathrm{h}, t=2.05 \mathrm{~s}$ resultant displacement (mm)

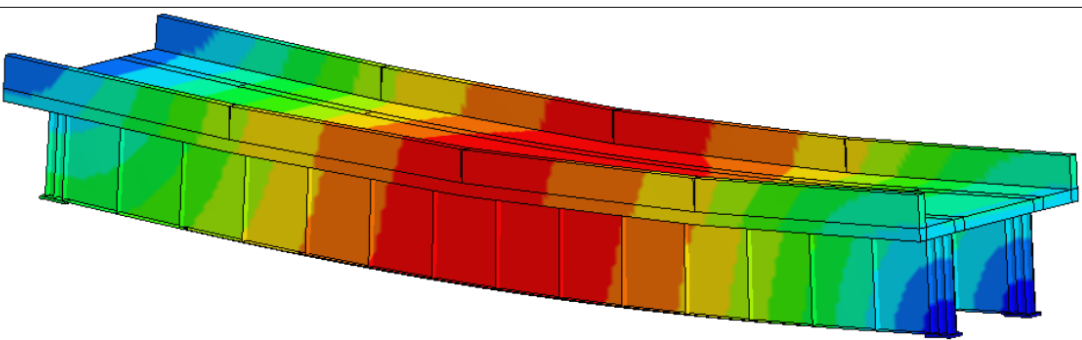

21-meter length bridge, $v=260 \mathrm{~km} / \mathrm{h}, t=2.95 \mathrm{~s}$ resultant displacement (mm)

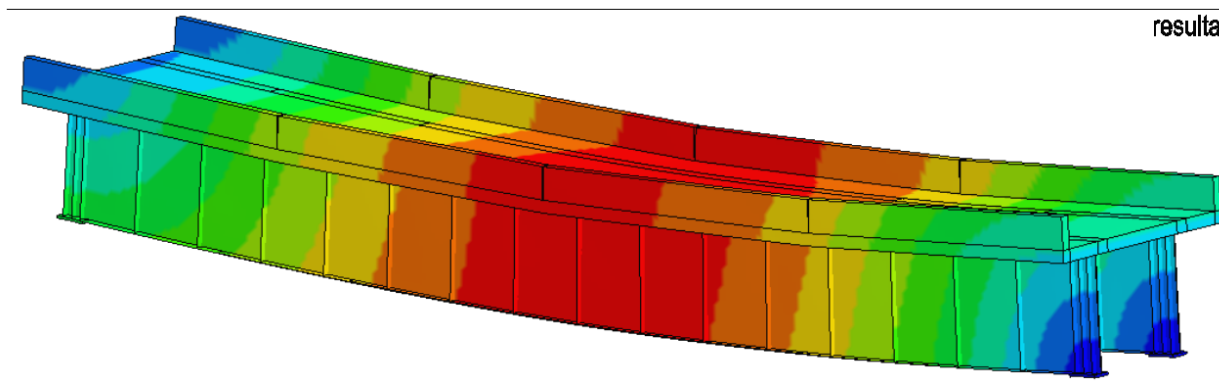

24-meter length bridge, $v=240 \mathrm{~km} / \mathrm{h}, t=3.25 \mathrm{~s}$

sultant displacement (mm)

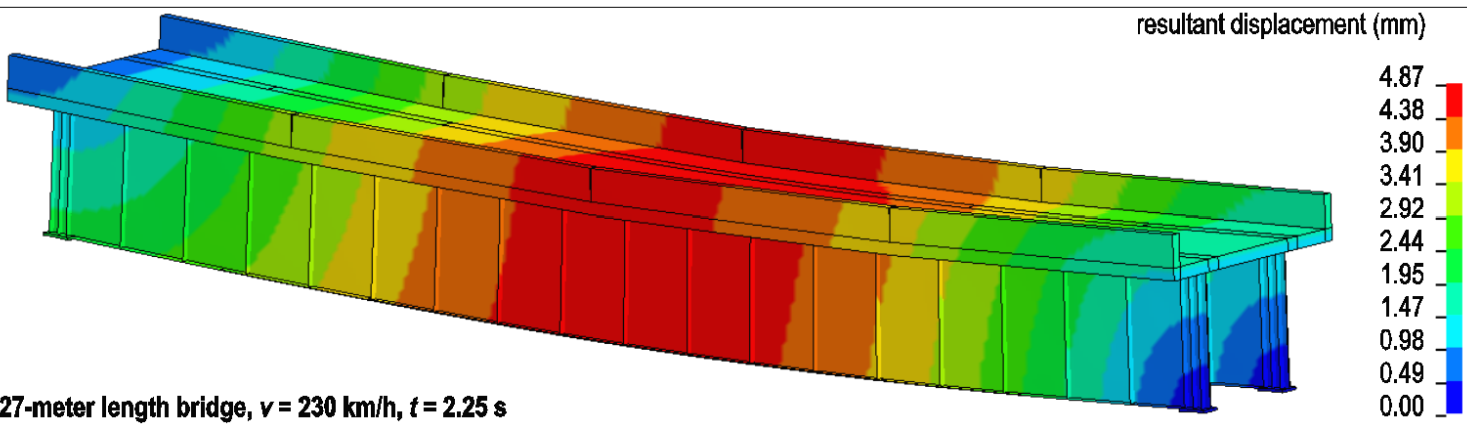

Figure 8: Contours of the resultant displacement for the bridges under consideration. Scale coefficient $100 \times$ for displacements. 
Generally, the paper presents the application possibilities of the proposed method for modelling and simulating the transient vibrations of a bridge-track-train system using CAE systems. Authors carried out several analyses of a series of single-span simply supported steel-concrete bridges subjected to a high-speed train. A series of bridges considered in the paper does not actually exist, however these bridges were adopted in accordance with the Polish Standards. Authors decided to use them in FE modelling due to their simplicity and easy modification. It allows Authors to develop the bridge FE models in a relatively short time and to focus on the other parameters of analysis, e.g. velocity. Simulations were conducted for a velocity range of $200-300 \mathrm{~km} / \mathrm{h}$. Resonant velocities were clearly evident for some cases, especially for the shortest bridge - 15-metre length - since its length was similar to the spacing of the bogies on the carriages. Obtained results can be considered both in qualitative terms - the span length influence on the bridge behaviour (deflections, resonant velocity) - or in quantitative terms - referencing the results presented in the paper to the other similar bridges. Moreover, results presented in the paper show that resonant velocity is clearly evident for some cases.

In addition, the proposed approach permits full visualization of a bridge's behaviour taking into account not only deflections but also, for example, the state of stress in its individual components, such as the main beams or the reinforced concrete platform.

\section{REFERENCES}

[1] Klasztorny, M.; Szurgott, P. (2011). Modelling and numerical simulation of symmetric vibrations of the KNI 140070 viaduct - ballasted track - ICE-3 train system, Proceedings of the $8^{\text {th }}$ International Conference on Structural Dynamics, 1129-1136

[2] Klasztorny, M. (1987). Vibrations of Single-track Railway Bridges Under High-speed Trains, Wroclaw University of Technology Press, Wroclaw

[3] Klasztorny, M. (2005). Dynamics of Beam Bridges Loaded by High-speed Trains, WNT Publishing, Warsaw

[4] Cheng, Y. S.; Au. F. T. K.; Cheung, Y. K. (2001). Vibration of railway bridges under a moving train by using bridge-track-vehicle element, Engineering Structures, Vol. 23, No. 12, 1597-1606, doi:10.1016/S0141-0296(01)00058-X

[5] Au, F. T. K.; Wang, J. J.; Cheung, Y. K. (2001). Impact study of cable-stayed bridge under railway traffic using various models, Journal of Sound and Vibration, Vol. 240, No. 3, 447-465, doi: $10.1006 /$ jsvi.2000.3236

[6] Zhang, Q.-L.; Vrouwenvelder, A.; Wardenier, J. (2001). Numerical simulation of train-bridge interaction dynamics, Computers \& Structures, Vol. 79, No. 10, 1059-1075, doi:10.1016/S00457949(00)00181-4

[7] Song, M.-K.; Choi, C.-K. (2002). Analysis of high-speed vehicle-bridge interactions by a simplified 3-D model, Structural Engineering and Mechanics, Vol. 13, No. 5, 505-532, doi: $10.12989 / \mathrm{sem} .2002 .13 .5 .505$

[8] Song, M.-K.; Noh, H.-C.; Choi, C.-K. (2003). A new three-dimensional finite element analysis model of high-speed train-bridge interactions, Engineering Structures, Vol. 25, No. 13, 16111626, doi:10.1016/S0141-0296(03)00133-0

[9] Xia, H.; Zhang, N.; de Roeck, G. (2003). Dynamic analysis of high speed railway bridge under articulated trains, Computers \& Structures, Vol. 81, No. 26-27, 2467-2478, doi:10.1016/S00457949(03)00309-2

[10] Lee, Y.-S.; Kim, S.-H.; Jung, J. (2005). Three-dimensional finite element analysis model of highspeed train-track-bridge dynamic interactions, Advances in Structural Engineering, Vol. 8, No. 5, 513-528, doi:10.1260/136943305774858034

[11] Rigueiro, C.; Rebelo, C.; da Silva, L. S. (2006). Modelling the interaction effects of the highspeed train-track-bridge system using Adina, Proceedings of the $5^{\text {th }}$ International Conference on Mechanics and Materials in Design, 14 pages 
[12] Liu, K.; de Roeck, G.; Lombaert, G. (2009). The effect of dynamic train-bridge interaction on the bridge response during a train passage, Journal of Sound and Vibration, Vol. 325, No. 1-2, 240251, doi:10.1016/j.jsv.2009.03.021

[13] Mikheev, G.; Krugovova, E.; Kovalev, R. (2010). Railway vehicle and bridge interaction: Some approaches and applications, WIT Transactions on The Built Environment, Vol. 114, 593-604, doi: $10.2495 / \mathrm{CR} 100551$

[14] Zhai, W.; Xia, H.; Cai, C.; Gao, M.; Li, X.; Guo, X.; Zhang, N.; Wang, K. (2013). High-speed train-track-bridge dynamic interactions - Part I: Theoretical model and numerical simulation, International Journal of Rail Transportation, Vol. 1, No. 1-2, 3-24, doi:10.1080/ 23248378.2013.791498

[15] Podworna, M.; Klasztorny, M. (2014). Vertical vibrations of composite bridge/track structure high-speed train systems - Part 1: Series-of-types of steel-concrete bridges, Bulletin of the Polish Academy of Sciences: Technical Sciences, Vol. 62, No. 1, 165-179, doi:10.2478/bpasts-2014-0018

[16] Podworna, M.; Klasztorny, M. (2014). Vertical vibrations of composite bridge/track structure high-speed train systems - Part 2: Physical and mathematical modelling, Bulletin of the Polish Academy of Sciences: Technical Sciences, Vol. 62, No. 1, 181-196, doi:10.2478/bpasts-2014-0019

[17] Salcher, P.; Adam, C. (2015). Modeling of dynamic train-bridge interaction in high-speed railways, Acta Mechanica, Vol. 226, No. 8, 2473-2495, doi:10.1007/s00707-015-1314-6

[18] Cantero, D.; Arvidsson, T.; O’Brien, E.; Karoumi, R. (2016). Train-track-bridge modelling and review of parameters, Structure and Infrastructure Engineering, Vol. 12, No. 9, 1051-1064, doi: $10.1080 / 15732479.2015 .1076854$

[19] Klasztorny, M.; Szurgott, P. (2012). Modeling and simulation of bridge-track-train systems at high service velocities with LS-DYNA, Proceeding of the $12^{\text {th }}$ International LS-DYNA Users Conference, 14 pages

[20] Szurgott, P. (2012). Modelling and numerical analysis of the reinforced concrete viaduct under the Eurocity EC-114 train, Journal of KONES Powertrain and Transport, Vol. 19, No. 2, 515524, doi: $10.5604 / 12314005.1138271$

[21] Szurgott, P.; Klasztorny, M. (2011). Modelling and numerical simulation of symmetric vibrations of the KNI 140070 viaduct - RHEDA track - ICE-3 train system, Proceedings of the $19^{\text {th }}$ International Conference on Computer Methods in Mechanics, 2 pages

[22] Szurgott, P.; Klasztorny, M.; Grosel, J.; Wójcicki, Z. (2011). Experimental validation of numerical modelling of the bridge-track-moving train system, WIT Transactions on Modelling and Simulation, Vol. 51, 97-109, doi:10.2495/CMEM110101

[23] Szurgott, P.; Klasztorny, M.; Niezgoda, T. (2010). Modelling and numerical simulation of symmetric vibrations of the KNI 140070 viaduct-ballasted track-KTX train system, Journal of KONES Powertrain and Transport, Vol. 17, No. 3, 415-422

[24] Siemens Transportation Systems. High Speed Trainset Velaro E for Spanish National Railways RENFE, from $h t t p: / / w w w . s i e m e n s . c o m / m o b i l i t y$, accessed on 12-08-2012

[25] Jones, R. M. (2014). Mechanics of Composite Materials, $2^{\text {nd }}$ edition, Taylor \& Francis, New York

[26] Steel Consortium. Technical Information-Reinforcing Steel-Ribbed Bars, from http://www.konsorcjumstali.com.pl/kategorie/prety_zebrowane, accessed on 9-12-2019

[27] Niemierko, A.; Kłosiński, B.; Sokołowski, J. (2009). Reinforcing the Track and the Subgrade in the Approach Zones to Engineering Objects (in Polish), Project No. M1-123, Research Institute for Roads and Bridges, Warsaw

[28] PN-H-84027-07. (1984). Steel for Rail-engineering, Normal rails, Sorts, Polish Committee for Standardization, Warsaw

[29] Bachmann, H. (1995). Vibration Problems in Structures, Birkhäuser, Berlin

[30] Matsuura, A. (1979). Dynamic behavior of bridge girder for high speed railway bridge, Railway Technical Research Institute, Quarterly Reports, Vol. 20, No. 2, 70-76

[31] Siemens Transportation Systems. First Class Bogies, The Complete Programme for High-quality Railway Transportation, from http://www.siemens.com/mobility, accessed on 12-08-2012

[32] Steimel, A. (2008). Electric Traction - Motion Power and Energy Supply: Basics and Practical Experience, Oldenbourg Industrieverlag $\mathrm{GmbH}$, München

[33] LS-DYNA V971 R4 Beta. (2009). Keyword User's Manual, LSTC, Livermore

[34] Bernacki, P. (2012). Influence of Span Length of Composite Bridge on Dynamic Response of Bridge - track - high-speed train system, MSc Thesis, Military University of Technology, Warsaw 